\title{
The representation of personal memory in Alan Berliner's First Cousin Once Removed
}

María del Rincón, Efrén Cuevas and Marta Torregrosa

Postprint version

Reference: María del Rincón, Efrén Cuevas and Marta Torregrosa, “The representation of personal memory in Alan Berliner's First Cousin Once Removed", Studies in Documentary Film, 2018, vol. 12, n. 1, pp. 16-27. DOI: 10.1080/17503280.2017.1399575

The Version of Record of this manuscript has been published and is available in Studies in Documentary Film, 2018: https://doi.org/10.1080/17503280.2017.1399575

\begin{abstract}
This article intends to analyze the representation of personal memory in Alan Berliner's film First Cousin Once Removed. The film serves as an innovative proposal in the filmic representation of personal memory, going beyond the most obvious topic of the film - the biography of Berliner's second uncle, suffering from Alzheimer's - and presenting us with a study of personal memory through the use of cinematic language. After a brief overview of how personal memory is represented in cinema, we first examine the film's thematic lines and narrative structure, proceeding afterwards to a closer analysis of its representation of the most relevant features of personal memory: subjectivity, complex temporality and performativity. Berliner explores these features in the film with insight: he emphasizes the subjective/autobiographical nature of memory work; he frames his portrait of Edwin Honig within complex temporal coordinates, where the past and present become indiscernible; and builds a self-reflexive film that emphasizes the performative character of memory and of its filmic representation.
\end{abstract}

Keywords: Documentary; Memory; Subjectivity; Performativity; Temporal indiscernibility; Alan Berliner

Documentary cinema often presents memory as being collective, social or cultural in nature; in this article, however, we propose to focus on the representation of memory as a human faculty, that is, as personal memory, through the analysis of a specific case, Alan Berliner's documentary, First Cousin Once Removed. Premiering in 2012 at the New York Film Festival, and awarded the Grand Prix of the prestigious International Documentary Film Festival of Amsterdam (IDFA), this film presents an insightful study of the main qualities of personal memory through the resources of cinematic language. For this analysis, we first set up a brief theoretical framework for the representation of memory in cinema, then we address the thematic and narrative coordinates of Berliner's film. Once we have established these bases, we examine the way in which personal memory is represented in the film in greater detail, by exploring its main features: subjectivity, temporal indiscernibility and performativity. 


\section{Representing personal memory in cinema: films of memory}

There are many different ways in which the concept of memory has been used in relation to cinema, mainly by resorting to a metaphorical understanding of the way they are connected. On the one hand, there are various metaphorical approaches to a definition of memory that use a similitude between memory and the cinematographic technique (Roediger 1980; Draaisma 2000). These explanations propose an understanding of memory rooted in some characteristics of cinematic recording, such as the inscription and storage of memories. These metaphors permeated everyday language, giving rise to an understanding of memory as an immutable and storable phenomenon (Radstone 2010, 327; Hoskins 2011, 21). On the other hand, the nature of film has also been explained comparing it to memory, resulting in certain theories about memory applied to film and visual studies: collective memory (Erll and Nünning 2010), prosthetic memory (Landsberg 2004), postmemory (Hirsch 2008). Other studies try to point out how memory and film influence each other, as in the theory of mediated memories proposed by Van Dijck (2007). This latter approach states that film configures both our personal and cultural identity in the same way that the nature and characteristics of memory influence the film medium. Thus, memory mediated through cinema manages to convey its communicative character to a wide audience.

These theories that relate film and memory - be it as a metaphorical relation or as the mediated memories theory - tend to consider memory as a completed object, as a stable and finished product that can be preserved and shared. That is why these theories focus mainly on analysing the remembered content of films, the rememorized events. As a consequence, their understanding of memory leads to the analysis of the representation of the historical past or to narratives about collective trauma, leaving aside a study of the concept and its relationship with cinema linked to a personal understanding of the act of memory.

When focusing on personal memory, it has become commonplace in contemporary theories to stress understanding it as a process, considering the act of remembrance as a reconstructive action of a creative sort (Radstone and Hodgkin 2003). The representation that our memory makes of the past is, in itself, an actualization of an already absent reality. This actualization can be shared via an external representation. Films constitute a privileged medium for generating these external representations because by their nature they grant us the power of generating representations, not only of the content of memories, but also of the act of remembering itself. These external representations of personal memory can be found sensu stricto in a limited corpus of films that authors such as MacDougall (1998), Ciancio (2013) or Grass Kleiner (2009) have termed as 'films of memory', whether fiction or documentary films. The main topic of these films is memory, understood as the human action through which the characters remember some events from their past. 
These films of memory use the specific tools of cinema to offer a representation of the nature of personal memory. As we proposed previously (2017), these films resort to three main ways of representing the qualities of personal memory:

(1) Subjectivity. Because memory is a personal action, films of memory do not focus on the representation of past events, but rather on the images and narrative structures that preserve the necessary bond between individuals and their memories. Therefore, they frequently employ first-person narration, especially in documentaries.

(2) Performativity. Aware of the performative character of memory, these films propose a narrative and a representation sustained by this characteristic. Memory builds itself as it happens and establishes a relation between the filmmaker, the characters and the spectator.

(3) Temporal indiscernibility. The temporality of memory is grounded on the personal experience of the duration of time, which finds consonance with the temporality of cinema. Thus, films of memory are constructed following a complex temporal logic, similar to that of memory when it actualizes past events, bringing the past and the present together. They tend to follow a non-causal narrative structure, which manages to capture an indiscernibility between past and present, able to reflect the workings of human memory.

Following this overview, necessarily succinct, of how cinema represents personal memory, we now move on to the analysis of the film First Cousin Once Removed, beginning with an examination to its main thematic and narrative features.

\section{Thematic lines and narrative approach}

First Cousin Once Removed presents the decline of the poet Edwin Honig - the filmmaker's second uncle - due to an advanced state of Alzheimer's disease, through the interaction with Alan Berliner, who becomes a second protagonist within the film. The main temporal framework covers the last five years of Honig's life, with footage shot by Berliner, into which an account of the poet's life is inserted using archival materials and interviews with people who have been part of his life. Berliner's film transcends the treatment that numerous documentaries, even those of an autobiographical nature, usually offer of Alzheimer's sufferers. ${ }^{1}$ Such works usually present the viewer with chronological accounts of the disease,

\footnotetext{
1 A comprehensive listing of Alzheimer's documentaries in English can be found at http://www.programsforelderly.com/documentaries-memory.php. The list includes several of an autobiographical character, such as Mom and Me, Forgetful Not Forgotten, Complaints of a Dutiful Daughter, or Sparky: Connection of Courage.
} 
along with archival material and interviews with relatives that illustrate the impact of the disease on their lives as well. However, First Cousin Once Removed departs from this approach, rising above a chronological narrative of the specific protagonist in order to examine personal memory as a theme, as well as its representation through cinema. Berliner has dealt with this issue in one form or another in all his films, linking it to questions of identity and time. The filmmaker conceives memory as the 'glue of life' that allows us to navigate through time without being disconnected from our own self (interview, February 22, 2013). In First Cousin Once Removed Berliner uses memory as the subject of the documentary and explores it by considering the way in which Alzheimer's has erased all of the relationships from which the identity of Edwin Honig had been constructed.

Two main currents make up the film: the reflections about memory and the biographical account of Honig's life; both are intermingled, becoming dependent on one another and blurring their boundaries. On the one hand, there is an elaborate reflection on memory as an identity generator. Memory is understood here as a process, as a human capacity, on which the film makes a proposal for its audiovisual representation. This ability to generate acts of memory is examined throughout the film via questions put to Honig about his memories, the filmmaker's own reflections, poems, and images. This conception of memory, as we will analyze below, is reflected by a complex temporality perceived subjectively, rather than by a linear temporality guided by causality. Upon losing his memory, Honig loses the capacity to build a chronological temporality and lives - as Berliner states - in a constant present, since without memory he can travel neither to his past, nor to his future (interview, February 22, 2013).

On the other hand, we find the biographical narrative about Edwin Honig, which Berliner builds on the memories of various witnesses. These memories are structured by means of a chronological temporality, which differentiates itself clearly from the way Honig's memory works. It is interesting that the filmmaker does not present this biographical narrative for the benefit of the film's viewers, but creates it for Honig himself. Nonetheless, as he narrates to Honig the story of his life, it leads viewers to an understanding of the importance of memory in their own experiences. As Berliner himself says to his uncle, 'I think a film about you will teach a lot of people what memory means' (04:48).

By interweaving these two thematic lines, Berliner does not limit himself to presenting his subject's experience and his chronology, but rather poses both a visual and a narrative representation of the way in which Edwin Honig's memory seems to be articulated. As Daniel Grinberg (2016) affirms, Berliner's documentary retains some elements of conventional documentaries - such as testimonies presented as talking busts, or archival materials used to illustrate the past - but is built mostly upon the disorder generated by the diseased memory, which seeks to represent itself, thus producing a unique aesthetic (73). 
Grinberg uses a suggestive neologism to describe this way of structuring the narration of the documentary: 'aesthetic of dis-ease' (73). This term can be understood in two ways: the disease affecting the memory and life of Honig, and that lack of comfort and ease that both Alzheimer's disease and the structure of the film generate in the viewer.

This way of structuring the film turns First Cousin Once Removed into an expressive cinematic manifestation of memory, which is here presented as a complex phenomenon that gives unity to personal identity. The set of filmic elements that make up the work reflects the complexity of the mnemonic act: from its fragmentary structure to the wide variety of visual and audio materials, and the editing which abounds in juxtapositions. All these formal decisions that Berliner presents confirm what Honig himself asserts in the documentary: 'There are things about the mind that you cannot describe' (09:30). The documentary is enunciated in an open voice - following Plantinga's typology (2005) - which does not seek to present a clear-cut explanation of how memory works or is lost, renouncing a position of narrative authority. The documentary does not, therefore, present an argument about memory to the spectators, but adopts a posture of exploration, emphasized by the self-reflexive construction of the film. It is, therefore, framed in the type of stories about memory that, as Lattanzi $(2011,111)$ affirms, moves away from narratives that propose images without obscurity and with full meaning, in favor of structures full of fissures and complicated processes of production. This approach manifests itself in the way in which the different social agents of the documentary are related. Berliner does not offer a speech on a topic to an audience, but rather establishes a dialogue, a conversation, with the subject of the documentary, to the point that he considers Honig the co-author of the documentary, as he says in an interview with Stein (2013). The filmmaker-narrator is not in possession of knowledge that he wants to transmit, but is acquiring it as the film unfolds, addressing both the subject of the documentary and the viewers, who are immersed in the exploration of memory as presented by the filmmaker.

The narrative of First Cousin Once Removed is structured like a collage, a structure full of fissures in which it is difficult to find evidence of any kind of chronological order. As the filmmaker himself points out, the decision not to follow a chronological structure is due to the need to generate ironic structures that mimic the progressive but non-linear logic of Alzheimer's (Rapold 2013). This disordered structure is created, in part, by the insertion of poetic passages in which Berliner constructs visual metaphors by using oral fragments of poems recited by Honig, along with other varied images. In addition, the meetings between Berliner and Honig are shown in a quick editing that juxtaposes different times, creating unique dialogue sequences. This characteristic approach to editing the film succeeds in representing the sense of lack of orientation and continuity proper to memory loss, as Grinberg (2016) affirms: 'The juxtapositions result in sharp temporal discontinuities, as Honig repeatedly ages and grows younger, alternates between states of relative health and 
evident debilitation, and vacillates between lucidity, partial awareness and confusion' (76). Nevertheless, despite the diversity of materials that make up this collage, the filmmaker maintains a strong coherence and a constant direction throughout the documentary. This is a characteristic feature of his work, as Carlos Muguiro (2002) points out: 'Although on the surface his films may appear saturated by an explosion of associations, shocks and sound and visual conflicts, underneath them there flows something like a raccord of thought, a powerful need for unity' (55).

\section{Features of the filmic representation of personal memory}

After addressing the thematic and narrative coordinates that allow us to situate the way memory is presented in First Cousin Once Removed, we will now study how the film represents the main qualities of personal memory: subjectivity, temporal indiscernibility and performativity.

\section{Subjectivity}

The open voice that articulates First Cousin Once Removed is closely linked with subjectivity, since it shows the connection with its enunciating subject, necessary for the documentary representation of memory. Personal memory, because it is a psychological and subjective phenomenon, does not 're-present' events as they happened, but selectively, as Traverso indicates (2005): 'Memory is eminently subjective; it remains anchored in the events we have seen, of which we have been witnesses, i.e. actors, and in the impressions they have left in our spirit' (19). Consequently, documentaries about the mnemonic act seek to understand the way in which the subject has personally experienced an event, and to this end they propose autobiographical narrations, in the first person, that allow the process of memory to be captured first hand (MacDougall 1998, 240).

However, the autobiographical documentaries are not limited to a solipsist narrative, by and about the filmmaker himself, but, as Alisa Lebow (2008, xi-xii) points out, they are often configured in the 'first person plural'. So too in First Cousin Once Removed, where the personal memories of Edwin Honig and Alan Berliner are intertwined. At first glance, one might conclude that the spectator is being presented with a biographical work - a portrait of the final years of Edwin Honig's life - but his perspective is more properly autobiographical, since it arises from a reflection on the memory of the filmmaker himself in dialogue with the failed memory of his second uncle. One could even speak of an 'autobiography in collaboration' of Edwin Honig, in which Berliner serves as a 'transcriber', as also happens in another of the filmmaker's works, Nobody's Business (Cuevas 2002, 43). 
This interweaving between each one's personal memories is observed throughout the film, suggesting a parallel between their lives. Thus, for example, after reminding Honig that he had two children and enquiring as to his relationship with them, Berliner introduces his own experience as a father and even introduces his son Eli in the film by means of archival materials and the child's interactions with Honig (48:00). On another occasion, Berliner confesses to Honig that he worries that he might lose his own memory, since several direct relatives have suffered Alzheimer's (including his father, who also appears in the film with symptoms of the disease [08:30, 38:00]). The filmmaker's voiceover weaves several shots in which Edwin seems to listen intently and be surprised at the confidence. Berliner asks for advice, and in this moment the image shifts to focus on the filmmaker, who listens mutedly and with concern to Honig's words: 'Prepare yourself, it is worse than you think' (08:49).

Berliner's conversations with Honig dig deeply into the subjective experience of memory. After a brief introductory scene of a poetic nature, the documentary starts with a sequence in which Berliner is observed going to visit Honig at his house. This first scene is constructed with fragments from different occasions in which the filmmaker visits the poet, and places the narrative within the subjective experience of memory, not in a story about Honig (01:10). Shortly afterwards, the filmmaker confesses to his second uncle that he wants to capture his experience, he wants to know what it is like to be Edwin Honig at that moment. The visual images are of a train leaving a station while Berliner poses his question. However, when Honig begins his explanation, the images of the train give way to others, blurred images of a roller coaster, doubly reinforcing Edwin's words explaining that there are things about the mind which are indescribable (09:00). Both of these visual metaphors, like the poems, are constant elements in the representation of Honig's memory, parallel to the images that show him remembering or trying to remember, in close-ups of his face that reveal his emotions. $^{2}$

Berliner's continuous questions are aimed at confronting Honig's memory with the account of his biography, which he builds through photographs, videos, diaries and the testimonies of people who knew him. These external proofs, regarded as receptacles of memory, serve as catalysts for those who have the capacity to actualize their past. But Honig is unable to recognize images of his relatives, his own image, or the stories told about him. Faced with the progressive and irreversible loss of his memory, the protagonist remains as if dispossessed of his own self, presenting himself as different characters. The film usually

${ }^{2}$ This memory embodied in the face of the subject is also especially evident in Berliner's experimental short film, 56 Ways of Saying I Do Not Remember, made before First Cousin Once Removed. The short is a compilation of the expressions used by Honig in confronting his own forgetfulness. 
reflects it, as Grinberg $(2016,77)$ affirms, as a discursive bifurcation that presents Honig's different 'selves' without integrating them, through an editing that juxtaposes images of the protagonist's past and present. This is very effectively shown in a scene that is structured as a poetic collage about dreams, in which a poem by Pessoa is recited in Portuguese, while Honig's English translation of the verses appear transcribed on the screen (53:44). The scene underscores the splitting of Honig's identity, as if the translation of the poem led Honig to suffer the fate of his translated verses: 'Recalling who I was, I see somebody else / In memory the past becomes the present / [...] My own memory is nothing, and I feel / That who I am and who I was / Are two contrasting dreams' (1998, 137).

\section{Temporal indiscernibility}

First Cousin Once Removed presents a complex temporality, portraying memory not as a way of observing a frozen and static past but showing the relationship between past, present and future with a temporal indiscernibility difficult to unravel, similar to the functioning of human memory. As Straub (2010) points out, memory is not equivalent to the past, but to the action of the subject who looks at the past from the perspective of the present (221). Therefore, personal recollection does not usually establish a strict distinction of time, but rather treats it as a constant flux (Murakami 2012, 3). Thus considered, the idea of time is conceived as a personal experience of duration, recalling the Greek concept of kairos, which is altogether different from the perception of time as a linear and static temporality. From a cinematic perspective, this temporal complexity undoubtedly refers to the Deleuzian imagetime, which can always be shown in the present without being deprived of its burden of past and future (1989, 98-102). A temporal structure of this kind acquires a labyrinthine character: the past is not stagnant in a time that is no longer, but continues to be affected by the present, to be recreated when it is invoked. This labyrinthine temporality is expressed in the cinema, continues Deleuze, through 'crystal-images', where the past and the present, the virtual and the present, are uniquely interwoven:

Since the past is constituted not after the present that it was but at the same time, time has to

split itself in two at each moment as present and past [...], it has to split the present in two heterogeneous directions, one of which is launched towards the future while the other falls into the past $(1989,81)$.

In Berliner's film, this labyrinthine temporality is achieved through the editing and use of archival images, coming from Honig's personal archive as well as from found footage. The editing of the documentary proposes a structure in which the different materials, filmed at different times, are juxtaposed, creating crystal-images in which the temporalities cannot be differentiated from one another by following a linear chronology. This is especially clear in the conversations between the filmmaker and Honig, shot over a period of five years, 
which are intermingled in such a way that it is difficult to give a chronology to the different faces of the character.

As Muguiro affirms, Berliner is a filmmaker who, from the perspective of the present, constantly appeals to memory and eternity, to the past and to the future:

This gives the feeling that Alan Berliner is moved by a Utopian project to amass all time into something that is a continuous present as a means of enduring. [...] [T] he past and the future, as two tectonic masses, two territories which will never be ours, clash together in Berliner's hands and before our eyes. $(2002,70)$

This clash between the past and the present acquires a singular protagonism when Honig sees some images of himself from the past, taken from different interviews in which he presents his achievements. Honig, in the present, acknowledges he does not know who the man speaking is, to which Berliner replies: 'He is the man who you once were' (06:40). In response, Honig declares himself unimpressed, since the man on the screen is trying to appear to be someone important. Later, other images of the past establish an implicit dialogue with his future - Honig's present reality, suffering from Alzheimer's - when they show an interview in which Honig fails to remember the title of one of the books he has published. Berliner juxtaposes images from this interview with shots of Honig's face watching it in silence (07:20). The moment of silence is lengthened in the reverse shot, and highlights both the performativity of the mnemonic act and the temporal relationship that seems to unite both shots in an indiscernible time.

The interplay between temporalities can also be understood in light of the types of signs used in films of memory, as proposed by David MacDougall (1998, 231-235). The scenes showing Edwin Honig can be interpreted as signs of survival, emphasizing the temporal passing that is perceived by Honig's physical exhaustion. The snapshots and home movies from the family archive can also be read as signs of survival, but in fact they become more clearly signs of absence. The photographs that Berliner shows to Honig, portraying his parents, grandparents and his brother Stanley, capture an acute feeling of an absence, echoing classical understandings of photography, such as the one proposed by Roland Barthes (1982). In Camera Lucida he refers to "the lacerating emphasis of the noeme ("that-has-been")' that makes the photograph tell about 'death in the future' $(1982,96)$. A similar effect occurs with the images from the family archive in First Cousin Once Removed. The moments presented in the photographs belong irrevocably to the past; some of the people shown in them no longer live; Honig himself is no longer the man he once was. Nevertheless, these images continue to have an effect on the present. Berliner delves into these images from the past, searching for some sign of the future that was going to happen to Honig, in an attitude similar to the one of Chris Marker's protagonist in La Jetée, who, in a time-loop searches for the future in memories (Muguiro 2002, 70-71). This effect is also emphasized when the 
documentary presents the testimonies of Honig's children and his ex-wife on the situations that led to their divorce, edited over a series of more contemporary images of Edwin, in an advanced state of his illness, asleep in his armchair (63:00).

First Cousin Once Removed also deals in a very productive way with the archive as a sign of absence through different visual metaphors representing forgetfulness and lack of memory. The most relevant example of this involves a sequence that begins with an image of an avalanche, symbolizing the total collapse of memories (56:40). This is followed by a scene in which we watch decomposing celluloid, interspersed with very brief images, previously seen throughout the documentary. These images, which have provided the film's structure, 'disappear in a long and endless thing', as Honig says in voiceover, like the diseased memory itself (57:08). The decomposition of the images indicates, as he also points out, that something is dead: memory.

\section{The performativity of memory}

As mentioned above, memory functions as an active process in which the mind reconstructs the past from the present in light of future expectations. Therefore, memory work implies a production and a performance. As Annete Kuhn (2002) says, "memory work is a conscious and purposeful performance of memory; it involves an active staging of memory; it takes an inquiring attitude towards the past and its (re)construction through memory" (157). This performative dimension is shown in films of memory through narratives with a marked selfreflexive character, which reveals the difficulty of remembering and the present nature of such action, combining the representation of the personal mnemonic act and the interpellation to the spectator about the nature and representation of memories. They actually fit into the broader category of 'performative documentaries,' a typology not necessarily related to memory originally proposed by Bill Nichols (1994). Stella Bruzzi (2000) has enriched the definition of this typology with a reading more relevant to memory work, stating that beyond the stress on the 'subjective aspects of a classically objective discourse' (Nichols 1994, 95), they present a construction that imitates the process followed by the protagonists of the film (2000: 135).

First Cousin Once Removed captures this performative character of memory construction, relying on both the temporal construction of the documentary and the relationship with the viewer. Berliner's film thus manages to create Deleuzian crystal-images to represent memory, combining as it does the temporal indiscernibility already analyzed with the involvement of the viewer through performativity. This approach is based on a clear self-reflexive strategy, built mainly from Berliner's autobiographical voice and an editing that makes visible the temporal mechanisms of the discourse. 
The documentary presents Honig's memory as continuously updating itself through his changing answers to the same question, formulated at different moments. When, for example, Berliner asks Honig if there is something he will never forget, the viewer witnesses the process of recollection that at one point actualizes the memory of the death of his brother Stanley, although later he is incapable of generating the same evocation upon being presented with an image of his brother (11:06). The construction of the film itself is shaped in a parallel way as a search for memory, as a process by which the memories of Honig are organized, only to later fall once more into oblivion. In this way, the film expands its focus beyond the portrait of Honig's disease to generating a broader reflection around the theme of memory under construction.

The performative dimension of the film extends to the viewers, who are invited to reproduce the mnemonic actions shown on the screen. Sometimes such interpellations are implicit, as when viewers observe Honig watching himself in an interview in which he does not remember the title of a book and wish they were able to help him remember (07:20). The close-ups of Honig confronting his inability to remember things perform a similar function. The camera approaches his face, establishing a rapport between the construction of the subject's memory and the viewers, as Waterson points out:

Prolonged close-ups of human faces not only provide us with an important part of the evidence (the chance to analyse non-verbal elements of communication), but also enable us as audience to do our share of the work as receptive, empathic listeners, sharing even if distantly in the event of the testifying. $(2007,70)$

In addition, when Honig speaks, he usually adopts a rhythmic and poetic cadence, which is shaped like a continuous performance in which his memories intermingle, producing apparently meaningless phrases. This mise en scene of the poetic language employed by Edwin, along with its fragmentary editing, appeals again to the viewers, moving them to give sense to what is perceived.

On other occasions, Berliner explicitly appeals to the viewers' own mnemonic experiences. The most obvious case occurs when he asks them, at the beginning of the film, to recall the words 'chair, tree and bird' (10:37). In the last scene of the film, superimposed on a long shot of Honig's room, Berliner asks the viewers by means of a superimposed text if they remember in the right order the words he asked them to remember at the beginning of the film (76:33). Now these three words challenge viewers in two ways: they are faced with the fallibility of their memories, since they usually do not remember the three words in the order given; but they also remember them loaded with the meaning gradually acquired throughout the documentary. Chair, tree and bird are indeed metaphors around which the different scenes that compose the documentary are embedded. Several scenes during the film place Honig in his armchair, from which he adopts a position of disinterest towards his own 
biography and his illness. Honig himself says at one point that he observes the world from there. The film also reflects directly on his loss of memory, comparing it with a tree that loses its leaves (25:10). Likewise the course of time is shown by a succession of shots of the tree at different times of the year. Finally, the documentary proposes a parallel between the birds, the music that Honig likes and the inarticulate sounds the poet emits in the final days of his life (59:20). Therefore, this final direct appeal of the film to the viewers does not remain a mere superficial resource to capture their attention, but involves them by inviting them to generate a reflection on their capacity for remembrance. In this way, the film creates a link between the viewers and the work; between them and, in a way, the filmmaker-author.

To briefly conclude, the analysis of First Cousin Once Removed presents us with an innovative proposal for the filmic representation of personal memory. The film addresses this issue through the interaction between the filmmaker and his relative, Edwin Honig, exploring through cinematic language the effects of Alzheimer's disease in his life. In order to do this, Berliner examines in the film the main features of personal memory: he emphasizes the subjective/autobiographical nature of all work involving memory; he frames his study in complex, labyrinthine temporal coordinates, where past and present become indiscernible; and he builds a clearly self-reflexive film, emphasizing the performative character of memory and of filmic representation.

\section{References}

Barthes, Roland. 1982. Camera Lucida. Reflections on Photography. New York: Hill and Wang.

Bruzzi, Stella. 2000. New Documentary: A Critical Introduction. London: Routledge.

Cuevas, Efrén. 2002. "Evolution and Contexts of the Films of Alan Berliner". In The Man without the Movie Camera: The Cinema of Alan Berliner, edited by Efrén Cuevas and Carlos Muguiro, 25-49. Madrid: Ediciones Internacionales Universitarias. http://dadun.unav.edu/bitstream/10171/3392/1/el\%20hombre\%20sin\%20camara\%2 0efren.pdf

Ciancio, María Belén. 2013. "Labyrinths and Lines of Memory in Documentary Film. Memoria del saqueo and Los rubios from a Philosophical Perspective." Latin American Perspectives 40(1): 101-113. doi: 10.1177/0094582X12460491

Deleuze, Gilles. 1989. Cinema 2. Minneapolis: University of Minnesota Press. 
Del Rincón María, Marta Torregrosa and Efrén Cuevas. 2017. "The Filmic Representation of Personal Memory: The Films of Memory." ZER 22 (42): 175-188. doi: 10.1387/zer.17842

Draaisma, Douwe. 2000. Metaphors of Memory: A History of Ideas about the Mind. Cambridge, UK: Cambridge University Press.

Erll, Astrid, and Ansgar Nünning. 2010. A Companion to Cultural Memory Studies. BerlinNew York: De Gruyter.

Grass Kleiner, Milena. 2009. "Imagen latente y Los rubios: Performatividad Cinematográfica y Estética de la Memoria en el Cine Latinoamericano." PhD diss., Universidad de Chile. http://repositorio.uchile.cl/tesis/uchile/2009/grass_m/html/index-frames.html

Grinberg, Daniel. 2016. "Fading in the Frame: the Epistemology and Ethics of Documenting Alzheimer's Bodies." Studies in Documentary Film 10 (1): 71-86. doi:10.1080/17503280.2016.1171685

Hirsch, Marianne. 2008. "The Generation of Postmemory." Poetics Today 29 (1): 103-128. doi: 10.1215/03335372-2007-019

Kuhn, Annete. 2002. Family Secrets: Acts of Memory and Imagination. London: Verso.

Hoskins, Andrew. 2011. "Media, Memory, Metaphor: Remembering and the Connective Turn." Parallax 17(4): 19-31. doi: 10.1080/13534645.2011.605573

Landsberg, Alison. 2004. Prosthetic Memory. The Transformation of American: Remembrance in the Age of Mass Culture. New York: Columbia University Press.

Lattanzi, María Laura. 2011. "Nuevas construcciones y desmantelamientos de la memoria en tres documentales de cine autobiográfico argentino." Revista Aisthesis 49: 101-112. http://dx.doi.org/10.4067/S0718-71812011000100006

Lebow, Alisa S. 2008. First Person Jewish. Minneapolis: University of Minnesota Press.

MacDougall, David. 1998. "Films of Memory." In Transcultural Cinema, edited by David Macdougall, 231-244. Princeton: Princeton University Press.

Muguiro, Carlos. 2002. "The Filmmaker's Hands: Notes on the Editing and Film Legacy in Alan Berliner's Work." In The Man without the Movie Camera: The Cinema of Alan Berliner, edited by Efrén Cuevas and Carlos Muguiro, 53-66. Madrid: Ediciones Internacionales Universitarias. http://dadun.unav.edu/bitstream/10171/27902/1/5178.muguiro\%20sin.pdf

Murakami, Kyoko. 2012. "Time for Memory: Beyond Spatial Metaphors?" Culture \& Psychology 18 (1): 3-13. doi: 10.1177/1354067X11427468 
Nichols, Bill. 1994. Blurred Boundaries: Questions of Meaning in Contemporary Culture. Bloomington: Indiana University Press.

Pessoa, Fernando. 1998. Poems of Fernando Pessoa. Translated and edited by Edwin Honig and Susan M. Brown. San Francisco CA: City Lights Books.

Plantinga, Carl R. 2005. "What a Documentary Is, After All." Journal of Aesthetics and Art Criticism 63 (2): 105-117. http://www.jstor.org/stable/3700465

Radstone, Susannah. 2010. "Cinema and Memory." In Memory: Histories, Theories, Debates, edited by Susannah Radstone and Bill Schwarz, 325-342. New York: Fordham University Press.

Radstone, Susannah, and Katharine Hodgkin. 2003. Regimes of Memory. London: Routledge.

Rapold, Nicholas. 2013. "A Descent Chronicled with care. 'First Cousin Once Removed' Documents Edwin Honig's Life.” The New York Times, September 15.

Roediger, Henry. 1980. "Memory Metaphors in Cognitive Psychology." Memory \& Cognition 8 (3): 231-246.

Stein, Sophia. 2013. "First Cousin, Once Removed: a Conversation with Alan Berliner." Cultural Weekly, September 19. http://www.culturalweekly.com/first-cousinremoved-conversation-alan-berliner/

Straub, Jürgen. 2010. "Psychology, Narrative and Cultural Memory: Past and present.” In A Companion to Cultural Memory Studies, edited by Astrid Erll, 215-228. Berlin: De Gruyter.

Traverso, Enzo. 2005. Le Passé, mode d'emploi: Histoire, mémoire, politique. Paris: La Fabrique.

Van Dijck, José. 2007. Mediated Memories in the Digital Age. Stanford CA: Stanford University Press.

Waterson, Roxana. 2007. "Trajectories of Memory: Documentary Film and the Transmission of Testimony." History and Anthropology 18 (1): 51-73. doi: 10.1080/02757200701218239 